\title{
ADAM17-Mediated Ectodomain Shedding of Toll-Like Receptor 4 as a Negative Feedback Regulation in Lipopolysaccharide-Activated Aortic Endothelial Cells
}

\author{
Won Seok Yang ${ }^{\mathrm{a}} \quad$ Jin Ju Kim ${ }^{\mathrm{b}} \quad$ Mee Jeong Lee $^{\mathrm{c}} \quad$ Eun Kyoung Lee ${ }^{\mathrm{d}} \quad$ Su-Kil Park \\ aDivision of Nephrology, Department of Internal Medicine, Asan Medical Center, University of Ulsan \\ College of Medicine, Seoul, bAsan Institute for Life Sciences, Seoul, 'Department of Pediatrics, Dankook \\ University College of Medicine, Cheonan, 'Division of Nephrology, Department of Internal Medicine, \\ Dankook University College of Medicine, Cheonan, Korea
}

\section{Key Words}

A disintegrin and metalloprotease 17 - Aortic endothelial cells - Ectodomain shedding • Lipopolysaccharide $\cdot$ Toll-like receptor 4

\begin{abstract}
Background/Aims: Lipopolysaccharide (LPS)-activated monocytes/macrophages develop endotoxin tolerance in part by reducing cell surface toll-like receptor 4 (TLR4) through cluster of differentiation 14 (CD14)-dependent endocytosis. In case of endothelial cells, CD14 is expressed in low copy numbers as compared with monocytes/macrophages. Thus, we explored how endothelial cells regulate TLR4 expression after LPS stimulation. Methods: Cultured human aortic endothelial cells (HAECs) were treated with LPS. TLR4 expression was analyzed by Western blot analysis and immunofluorescence staining. A disintegrin and metalloprotease 17 (ADAM17) activity was measured using a fluorescent substrate. Results: TLR4 in cell lysate began to decrease within 30 min of LPS treatment with a maximal reduction at $2 \mathrm{~h}$, and it was accompanied by an increase of $\mathrm{N}$-terminal fragment of TLR4 in culture supernatant, indicating ectodomain shedding of the receptor. LPS activated p38 mitogenactivated protein kinase (p38 MAPK) and ADAM17, while LPS-induced ADAM17 activation was inhibited by SB203580, a p38 MAPK inhibitor. LPS-induced ectodomain shedding of TLR4 was attenuated by siRNA depletion of ADAM17 as well as TAPI-2 (an inhibitor of ADAM family) and SB203580. LPS pretreatment resulted in a blunted response of p38 MAPK activation to further LPS stimulation. In the cells depleted of ADAM17, LPS-induced p38 MAPK activation was prolonged and LPS-induced intercellular adhesion molecule-1 expression was potentiated. Conclusion: HAECs respond to LPS by rapid shedding of the ectodomain of TLR4 and thereby reduce the responsiveness to subsequent LPS exposure. ADAM17, downstream of p38 MAPK, is implicated in the ectodomain cleavage of TLR4.
\end{abstract}




\section{Cellular Physiology Cell Physiol Biochem 2018;45:1851-1862 \\ \begin{tabular}{l|l} 
and Biochemistry Published online: March 05, 2018 & $\begin{array}{l}\text { DOI: } 2018 \text { The Author(s). Published by S. Karger AG, Basel } \\
\text { www.karger.com/cpb }\end{array}$
\end{tabular} \\ Yang et al.: Ectodomain Shedding of TLR4 in Response to Lipopolysaccharide}

\section{Introduction}

In Gram-negativebacteremia, monocytes/macrophagesinteractwithlipopolysaccharides (LPS) and release proinflammatory cytokines to eradicate the invading bacteria [1]. Massive release of cytokines, however, may cause multiorgan failure and even death [1,2]. Accordingly, the response to LPS should be tightly regulated.

Downregulation of cell surface receptor is one of the defense mechanisms to avoid excessive inflammation. It can be accomplished by regulating biosynthesis, trafficking to the cell surface or degradation of the receptor. Receptor degradation occurs in endosomes and lysosomes following endocytosis [3]. Ectodomain shedding of the receptor also rapidly decreases the number of effective receptors [4]. In endothelial cells [5], for example, tumor necrosis factor- $\alpha(\mathrm{TNF}-\alpha)$ binding to its receptor leads to internalization of ligand-receptor complex. The receptor endocytosis is linked to activation of nuclear factor $\kappa \mathrm{B}$, but the resultant loss of cell surface receptors desensitizes the cells to TNF- $\alpha$. In addition, TNF- $\alpha$ signaling activates a disintegrin and metalloprotease (ADAM) 17 which cleaves the ectodomain region of TNF receptors [6]. Ectodomain shedding of the receptors not only reduces the number of receptor on the cell surface but also releases decoy receptors that compete with cell surface receptors for ligand binding [4].

LPS exerts its cellular effects by binding to toll-like receptor 4 (TLR4) on the cell surface [7]. In the bloodstream, LPS-binding protein captures LPS and transfers it to cluster of differentiation 14 (CD14). Formation of LPS-CD14 complex facilitates the transfer of LPS to TLR4/myeloid differentiation-2 complex which leads to dimerization of the receptor [8]. Thereafter, a cytoplasmic Toll/interleukin-1 receptor domain of TLR4 recruits adaptor molecules TIRAP, MyD88 and IRAK kinases activating the signal pathway to produce inflammatory cytokines and adhesion molecules such as intercellular adhesion molecule-1 (ICAM-1) [7, 9]. In monocytes/macrophages, activated TLR4 complexes are internalized into endosomes where TRAM and TRIF are recruited to TLR4, activating the signal pathway producing type I interferons [7]. Endocytosed TLR4 ultimately undergoes degradation within lysosomes [10]. The loss of cell surface TLR4 by endocytosis desensitizes activated monocytes/macrophages to LPS [11,12].

The necessity of CD14 for cellular response to LPS depends on the concentration of LPS. Low concentrations of LPS require CD14 to activate MyD88-dependent pathway, but high concentrations ( $>10 \mathrm{ng} / \mathrm{ml}$ ) of LPS activate MyD88-dependent pathway even in the absence of CD14 $[13,14]$. To induce endocytosis of activated TLR4 linked to activation of TRAM-TRIF pathway, however, LPS requires CD14 even at high concentrations $[13,14]$.

Besides monocytes/macrophages, LPS interacts with endothelial cells lining the blood vessels. Endothelial cells also express TLR4 and are known to be activated by LPS through TLR4 $[15,16]$. However, LPS signaling in endothelial cells may not be the same with that in monocytes/ macrophages. While monocytes/macrophages abundantly express CD14 that is indispensable for endocytosis of activated TLR4, endothelial cells do express, but much lower level of CD14 [1719]. In macrophages and mast cells deficient of CD14, LPS stimulation was shown to primarily activate MyD88 pathway, but little activate TRAM-TRIF pathway that is linked to endocytosis of TLR4 $[13,20]$. Thus, endothelial cells might be different from monocytes/macrophages in the way of regulation of cell surface TLR4 following exposure to LPS.

TLR4 is one of type I transmembrane proteins. Recently, we found that TLR4 is subject to ectodomain shedding by ADAM10 when human aortic endothelial cells (HAECs) are treated with 1,25-dihydroxyvitamin $\mathrm{D}_{3}\left(1,25 \mathrm{D}_{3}\right)$ or Bay K8644, an L-type calcium channel agonist [16]. Ectodomain shedding of TLR4 resulted in desensitization of the cells to LPS stimuli. LPS is known to rapidly activate ADAM17 through p38 mitogen-activated protein kinase (p38 MAPK) pathway [21]. ADAM17 is also implicated in the ectodomain cleavage of diverse type I transmembrane proteins and shares many substrates with ADAM10 [22].

In the present study, we hypothesized that endothelial cells activated by LPS may downregulate the response to further LPS stimuli by shedding cell surface TLR4, and explored this possibility in HAECs.

\section{KARGER}




\section{Cellular Physiology Cell Physiol Biochem 2018;45:1851-1862

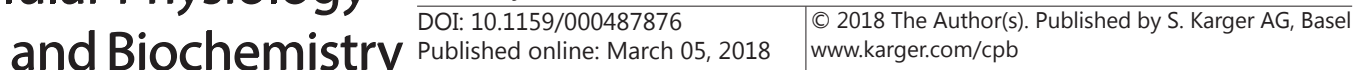 \\ Yang et al.: Ectodomain Shedding of TLR4 in Response to Lipopolysaccharide}

\section{Materials and Methods}

\section{Materials}

LPS (from Escherichia coli 0111:B4), dynasore and 4',6-diamidino-2-phenylindole dihydrochloride (DAPI) were from Sigma Chemical Co. (St. Louis, MO, USA). SB203580 and dimethyl sulfoxide (DMSO) were from EMD Chemicals (Darmstadt, Germany). TAPI-2 was from Cayman Chemical (Ann Arbor, MI, USA). Antibodies to human TLR4 (H-80: a rabbit polyclonal antibody against amino acids 242 - 321 of human TLR4; 76B357.1: a mouse monoclonal antibody against amino acids 100 - 200 of human TLR4), p38 MAPK, ICAM-1, ADAM10 and actin were from Santa Cruz Biotechnology (Santa Cruz, CA, USA). Antibody to human ADAM17 was from Abcam. Phospho-p38 MAPK (Thr180/Tyr182) was from Cell Signaling Technology (Denvers, MA, USA). ADAM17-siRNA, ADAM10-siRNA, TLR4-siRNA and control-siRNA (Ambion ${ }^{\circledR}$ ) were from Life Technologies (Paisley, UK). The fluorogenic substrate for ADAM17, 5-FAM-Ser-Pro-Leu-Ala-GlnAla-Val-Arg-Ser-Ser-Ser-Arg-Lys(5-TAMRA)- $\mathrm{NH}_{2}$, was from Enzo Life Sciences, Inc. (Farmingdale, NY, USA).

\section{Cell culture}

Primary HAECs were obtained from Lonza Walkersville, Inc. (Walkersville, MD, USA). Cells were cultured in EBM-2 endothelial growth basal medium (Lonza Walkersville, Inc.) and passaged 3-5 times. Before each experiment, the cells were rested in M199 Hank's medium (Life Technologies) containing 1\% FBS for $24 \mathrm{~h}$. Thereafter, the medium was replaced with serum-free M199 Hank's medium (Ca ${ }^{2+} 1.26$ mM) followed by the addition of signal inhibitors and LPS.

\section{Transfection of siRNA}

HAECs were seeded in 6-well plates and cultured for $24 \mathrm{~h}$. To prepare siRNA-lipofectamine complexes, siRNAs were incubated for 15 min with Lipofectamine ${ }^{\circledR}$ Reagent (Life Technologies) diluted in Opti-MEM ${ }^{\circledR}$ medium (Life Technologies) at room temperature. Transfection of siRNA was performed by adding the siRNA-lipofectamine complexes to the cells in serum-free culture medium and incubating the cells for $6 \mathrm{~h}$ at $37^{\circ} \mathrm{C}$ in a $\mathrm{CO}_{2}$ incubator. The cells were further cultured for $18 \mathrm{~h}$ in EBM-2 endothelial growth basal medium. Thereafter, the cells were rested for $24 \mathrm{~h}$ in M199 Hank's medium containing 1\% FBS and then subjected to the experiments.

\section{Western blot analysis}

Treated cells were washed with phosphate buffered saline (PBS) and incubated on ice for 10 min with cold lysis buffer (50 mM Tris- $\mathrm{HCl}, \mathrm{pH} 7.4,150 \mathrm{mM} \mathrm{NaCl}, 0.25 \%$ sodium deoxycholate, 1\% NP-40, protease and phosphatase inhibitors). The lysed cells were collected using a plastic cell scraper, transferred to a microcentrifuge tube and centrifuged at $4{ }^{\circ} \mathrm{C}(10,000 \times \mathrm{g})$ for $20 \mathrm{~min}$, and the supernatant was obtained as whole cell lysate. The cell lysates were separated by sodium dodecyl sulfate-polyacrylamide gel electrophoresis and transferred to an Immobilon-P membrane (Merck Millipore Co., Darmstadt, Germany). Then, the membrane was incubated with the primary antibody, followed by washing and further incubation with horseradish peroxidase conjugated secondary antibody. Thereafter, the protein bands were visualized using the enhanced chemiluminescence agent (Luminata ${ }^{\mathrm{TM}}$ Forte Western HRP Substrate; Merck Millipore Co.).

To detect TLR4 in culture medium of the treated cells, equal amounts of culture supernatants were concentrated 30-fold using Amicon ${ }^{\circledR}$ Ultra 10K device (Merck Millipore Co.). Thereafter, the samples were incubated with $5 \times$ sample buffer for $30 \mathrm{~min}$ at $37^{\circ} \mathrm{C}$ and subjected to immunoblot with anti-TLR4 antibody (76B357.1).

\section{Immunofluorescence staining}

TLR4 expression on the cell surface was examined by immunofluorescent staining. Treated cells were fixed with $4 \%$ paraformaldehyde for $10 \mathrm{~min}$, but not treated with cell membrane permeabilizing agent. To block the nonspecific binding, the cells were incubated for 60 min with $1 \%$ bovine serum albumin in PBS. Thereafter, the cells were incubated with a mouse antibody against the amino acids in the extracellular domain of human TLR4 (76B357.1, 1:100 dilution) overnight at $4{ }^{\circ} \mathrm{C}$, washed 3 times with PBS and then incubated with FITC-conjugated anti-mouse IgG secondary antibody. Immunostained cells were visualized using a confocal microscope. 


\section{Cellular Physiology Cell Physiol Biochem 2018;45:1851-1862 \begin{tabular}{l|l} 
and Biochemistry POI: 10.1159/000487876 & $\begin{array}{l}\text { (c) } 2018 \text { The Author(s). Published by S. Karger AG, Basel } \\
\text { www.karger.com/cpb }\end{array}$
\end{tabular}

\section{Metalloprotease activity assay}

To assess ADAM17 activity, we measured the metalloprotease activity in cell lysate using 5-FAM-SerPro-Leu-Ala-Gln-Ala-Val-Arg-Ser-Ser-Ser-Arg-Lys(5-TAMRA)- $\mathrm{NH}_{2}$, a fluorogenic substrate for ADAM17. FAM fluorescence of this substrate is quenched by the TAMRA group until they are separated by enzymatic cleavage. Treated HAECs were lysed and whole cell lysates were obtained as in Western blot analysis. Thereafter, $50 \mu \mathrm{l}$ of cell lysates $(20 \mu \mathrm{g})$ or cell lysis buffer (to measure background fluorescence) were incubated with $50 \mu \mathrm{l}$ of fluorogenic substrate in Hanks's balanced salt solution $(2 \mu \mathrm{M})$ at $37{ }^{\circ} \mathrm{C}$ for $60 \mathrm{~min}$. The fluorescent intensity was measured at 60 min using a fluorescence plate reader (SPECTRmax ${ }^{\circledR}$ GEMINI XS system; Molecular Devices, Sunnyvale, CA, USA) at $485 \mathrm{~nm}$ excitation and $535 \mathrm{~nm}$ emission wavelengths. Enzyme activity was expressed as a fold change in the fluorescence intensity compared with the control.

\section{Statistical analysis}

Data are presented as means \pm SE (standard error), with $n$ representing the number of different experiments. An analysis of variance with Scheffe's multiple-comparison test was used to determine statistically significant differences between groups. A p value of $<0.05$ was considered statistically significant.

\section{Results}

LPS induces ectodomain shedding of TLR4

To test whether LPS causes ectodomain shedding of TLR4, we incubated HAECs with LPS for up to $24 \mathrm{~h}$, and obtained the conditioned media and whole cell lysates. TLR4 in the cell lysate was measured by Western blot using a polyclonal antibody against TLR4. As shown in Fig. 1A, cellular TLR4 began to decrease within 30 min after LPS treatment with a nadir at about $2 \mathrm{~h}$, and then returned toward the basal level. To determine whether this reduction was caused by ectodomain shedding of the receptor, the conditioned medium was subjected to Western blot using a monoclonal antibody against the epitope in the N-terminus of TLR4. TLR4 immunoreactivity was detected in the culture supernatant and it appeared at $\sim 48 \mathrm{kDa}$ in size. The decrease in cellular TLR4 after LPS treatment was accompanied by an increase in $\mathrm{N}$-terminal fragment of TLR4 in the culture supernatant. LPS-induced ectodomain shedding of TLR4 was dose-dependent at the concentrations between $1 \sim 1,000 \mathrm{ng} / \mathrm{ml}$ (Fig. 1B).

To test the specificity of the TLR4 bands, we transfected the cells with control-siRNA or TLR4-siRNA and then incubated the cells with or without LPS. As shown in Fig. 1C, both TLR4 bands in

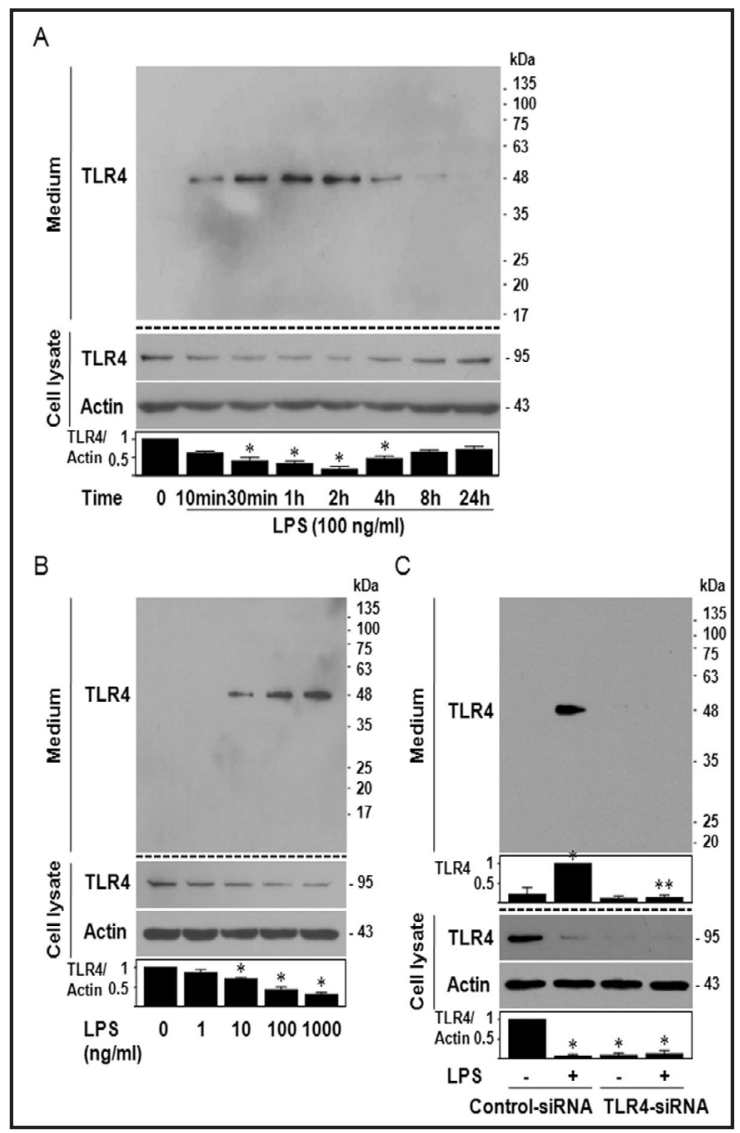

Fig. 1. LPS induces ectodomain shedding of TLR4. (A) HAECs were incubated with LPS (100 ng/ml) for different times. (B) HAECs were incubated with different concentrations of LPS for $60 \mathrm{~min}$. (C) HAECs were transfected with control-siRNA or TLR4-siRNA, and then incubated with or without LPS (100 ng/ml) for $60 \mathrm{~min}$. Cell lysates and culture supernatants were analyzed by Western blotting using a polyclonal antiTLR4 antibody (cell lysates) or a monoclonal antibody against the $\mathrm{N}$-terminal region of human TLR4 (culture media). ( $\mathrm{n}=3,{ }^{*} \mathrm{p}<0.05$ compared with control, ${ }^{* *} \mathrm{p}<0.05$ compared with control-siRNA plus LPS). 


\section{Cellular Physiology Cell Physiol Biochem 2018;45:1851-1862

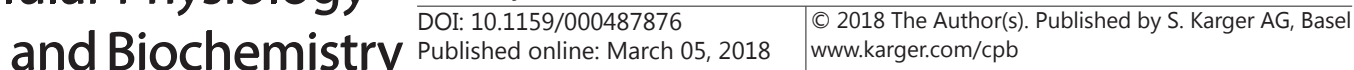 Yang et al.: Ectodomain Shedding of TLR4 in Response to Lipopolysaccharide}

the culture supernatant and whole cell lysate were markedly decreased by TLR4-siRNA transfection.

Involvement of p38 MAPK and ADAM17 in LPS-induced ectodomain shedding of TLR4

To test whether p38 MAPK and ADAM17 are implicated in the LPS-induced ectodomain shedding of TLR4, we preincubated the cells with or without SB203580 (an inhibitor of p38 MAPK) and TAPI-2 (an inhibitor of ADAM family), and then stimulated with LPS for 60 min. As shown in Fig. 2, both inhibitors prevented LPS-induced ectodomain shedding of TLR4.

To investigate the effect of specific depletion of ADAM17, we transfected the cells with controlsiRNA or ADAM17-siRNA and then incubated the cells with or without LPS. As shown in Fig 3A, depletion of ADAM17 abolished LPS-induced ectodomain shedding of TLR4.

Because ADAM10 was also reported to participate in LPS signaling [23], we examined the possible role of ADAM10 in LPSinduced ectodomain shedding of TLR4. As shown in Fig. 3B, LPS-induced ectodomain shedding of TLR4 was not affected by ADAM10 depletion.

\section{LPS activates p38 MAPK}

To determine the temporal changes of p38 MAPK activation after LPS treatment, we treated the cells with LPS for different times up to $180 \mathrm{~min}$. As shown in Fig. 4, p38 MAPK was markedly phosphorylated in $15 \mathrm{~min}$ after LPS treatment with a subsequent decrease in phosphorylation.
Fig. 2. LPS-induced ectodomain shedding of TLR4 is prevented by inhibitors of p38 MAPK and ADAMs. HAECs were preincubated with SB203580 (10 $\mu \mathrm{M})$, TAPI-2 $(10 \mu \mathrm{M})$ or DMSO (vehicle) for $30 \mathrm{~min}$, followed by incubation with LPS (100 ng/ml) for 60 min. Cell lysates and culture culture

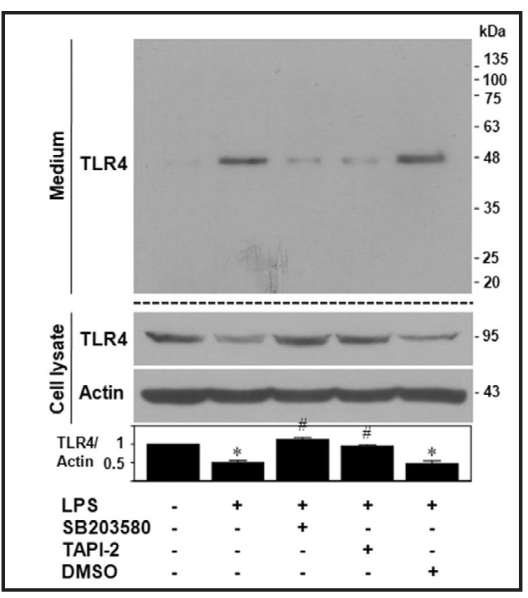
supernatants were analyzed by Western blotting using a polyclonal anti-TLR4 antibody (cell lysates) or a monoclonal antibody against the $\mathrm{N}$-terminal region of human TLR4 (culture media). ( $\mathrm{n}=3,{ }^{*} \mathrm{p}<0.05$ compared with control, ${ }^{*} \mathrm{p}<0.05$ compared with LPS).

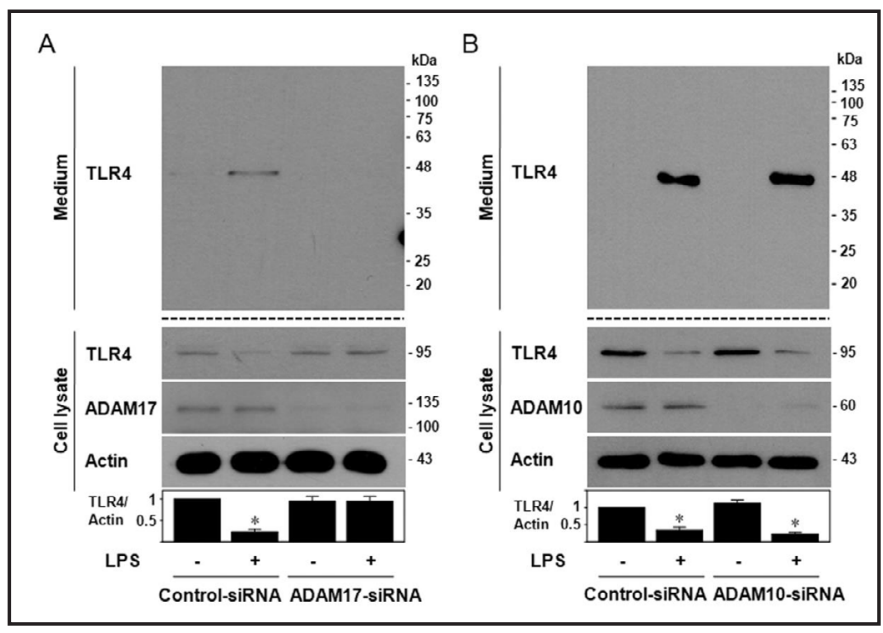

Fig. 3. ADAM17 is implicated in LPS-induced ectodomain shedding of TLR4. (A) HAECs were transfected with control-siRNA or ADAM17-siRNA, and then incubated with or without LPS (100 ng/ $\mathrm{ml})$ for $60 \mathrm{~min}(\mathrm{n}=4)$. (B) HAECs were transfected with controlSiRNA or ADAM10-siRNA, and then incubated with or without LPS $(100 \mathrm{ng} / \mathrm{ml})$ for $60 \mathrm{~min}(\mathrm{n}=3)$. Cell lysates and culture supernatants were analyzed by Western blotting using a polyclonal antiTLR4 antibody (cell lysates) or a monoclonal antibody against the $\mathrm{N}$-terminal region of human TLR4 (culture media). ( ${ }^{*} \mathrm{p}<0.05 \mathrm{com}-$ pared with control).

\section{LPS activates ADAM17 through p38 MAPK pathway}

Next, we examined whether LPS activates ADAM17, and whether $\mathrm{p} 38$ MAPK is implicated in the activation of ADAM17. ADAM17 activity was estimated by the increase in fluorescence intensity resulted from the enzymatic cleavage of a fluorogenic ADAM17 substrate. Because the substrate is not specific to ADAM17 and may also be cleaved by other ADAMs and matrix 


\section{Cellular Physiology Cell Physiol Biochem 2018;45:1851-1862 \begin{tabular}{l|l} 
and Biochemistry Published online: March 05, 2018 & $\begin{array}{l}\text { C) } 2018 \text { The Author(s). Published by S. Karger AG, Basel } \\
\text { www.karger.com/cpb }\end{array}$
\end{tabular}

metalloproteinases (MMPs), we compared the metalloprotease activity in the control cells and ADAM17-depleted cells. As shown in Fig. 5A, transfection of ADAM17-siRNA markedly depleted ADAM17 as compared with the control. In the cells transfected with control-siRNA, LPS increased the metalloprotease activity. In the cells depleted of ADAM17, however, LPS had little effect on the metalloprotease activity. Thus, the increase in the metalloprotease activity after LPS treatment represents mainly the increase in ADAM17 activity.

To test whether p38 MAPK is implicated in the LPS-induced ADAM17 activation, we preincubated the cells with or without SB203580, and stimulated them with LPS for $60 \mathrm{~min}$, and then measured the metalloprotease activity in the cell lysates. As shown in Fig. 5B, SB203580 abolished the stimulatory effect of LPS on ADAM17 activity.

LPS induces the loss of TLR4 on the cell surface

Ectodomain shedding of TLR4 should result in the reduction of TLR4 expression on the cell surface. To test whether this is the case, we examined the cell surface expression of TLR4 by immunofluorescent staining. The cells were preincubated with or without SB203580 or TAPI-2, and stimulated with LPS for $60 \mathrm{~min}$. After fixation but without permeabilization of the cell membrane, the cells were immunostained for TLR4 using a monoclonal antibody against the $\mathrm{N}$-terminal region of human TLR4. Our previous study demonstrated that this antibody is specific to TLR4 as the expression of TLR4 was markedly reduced in the cells depleted of TLR4 by siRNA transfection [24]. Consistent with the data of Western blot, LPS caused a decrease of TLR4 expression on the cell surface, and this effect of LPS was inhibited by SB203580 and TAPI-2 (Fig. 6).

Endocytosis does not account for the rapid loss of cell surface TLR4

In monocytes/macrophages, loss of cell surface TLR4 after exposure to LPS was mainly attributed to endocytosis and was prevented by dynasore (an inhibitor of endocytosis) [25]. Thus, we examined whether dynasore has such an effect in HAECs. In contrast to monocytes/macrophages, dynasore did not

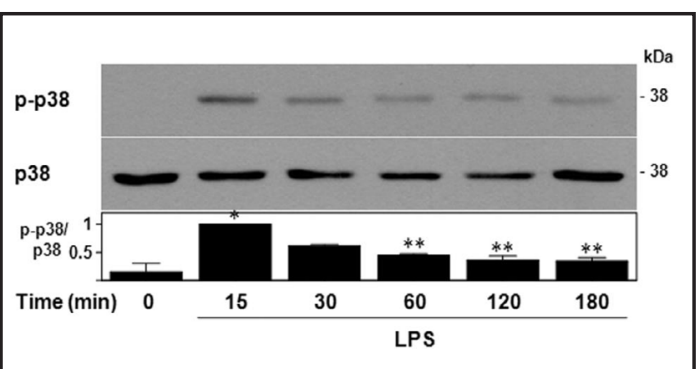

Fig. 4. LPS activates p38 MAPK. HAECs were incubated with LPS (100 $\mathrm{ng} / \mathrm{ml})$ for different times as indicated. Whole cell lysates were immunoblotted with antibody to p-p38 MAPK or p38 MAPK. ( $n=3$, ${ }^{*} \mathrm{p}<0.05$ compared with control, ${ }^{* *} \mathrm{p}<0.05$ compared with $15 \mathrm{~min}$ ).

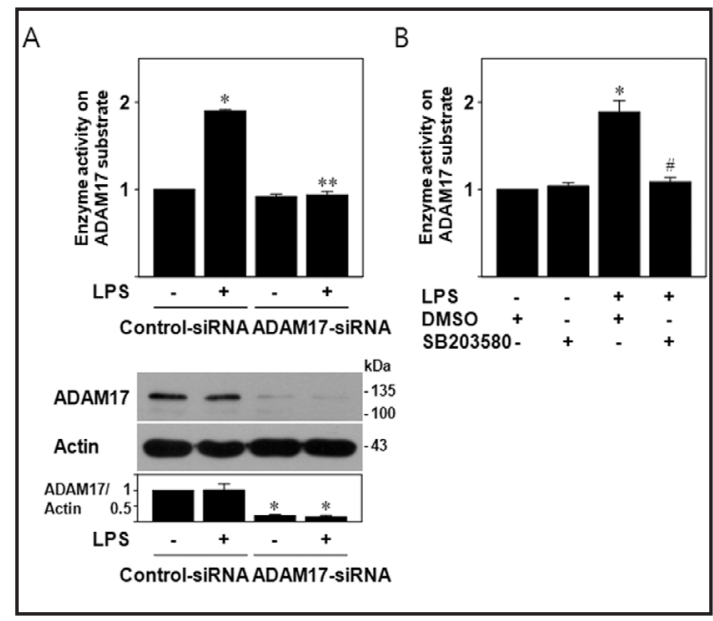

Fig. 5. LPS activates ADAM17 through p38 MAPK pathway. (A) HAECs were transfected with controlSiRNA or ADAM17-siRNA. Forty-eight hours later, the cells were treated with or without LPS (100 ng/ $\mathrm{ml}$ ) for $60 \mathrm{~min}$. (B) HAECs were preincubated with or without SB203580 $(10 \mu \mathrm{M})$ or DMSO (vehicle) for $30 \mathrm{~min}$, and then further incubated with or without LPS (100 ng/ml) for $60 \mathrm{~min}$. Cell lysates $(20 \mu \mathrm{g})$ were incubated with a fluorogenic ADAM17 substrate (a final concentration of $1 \mu \mathrm{M}$ ) for $60 \mathrm{~min}$ and fluorescent intensity was measured. Enzyme activity was expressed as a fold change in the fluorescence intensity compared with the control. ( $\mathrm{n}=5$, duplicated, ${ }^{*} \mathrm{p}<0.05$ compared with control, ${ }^{* *} \mathrm{p}<0.05$ compared with control-siRNA plus LPS, ${ }^{\#} \mathrm{p}<0.05$ compared with LPS) In the cells transfected with siRNA, cell lysates were immunoblotted with an antibody to ADAM17 or actin. (n=5, ${ }^{*} \mathrm{p}<0.05$ compared with control). 


\section{Cellular Physiology Cell Physiol Biochem 2018;45:1851-1862 \begin{tabular}{ll|l} 
and Biochemistry Published online: March 05, 2018 & $\begin{array}{l}\text { C } 2018 \text { The Author(s). Published by S. Karger AG, Basel } \\
\text { www.karger.com/cpb }\end{array}$
\end{tabular}

prevent the loss of cell surface TLR4 following LPS treatment (Fig. 7A).

We further examined whether inhibition of endocytosis increases shedding of TLR4 after LPS stimulation. The cells were preincubated with or without dynasore, and then stimulated with LPS for $60 \mathrm{~min}$. As shown in Fig. 7B, dynasore had no significant effect on LPSinduced ectodomain shedding of TLR4.

\section{LPS pretreatment attenuates the response to further LPS stimuli, while depletion of ADAM17 potentiates the cellular effects of LPS \\ To assess how the} ectodomain shedding of TLR4 affects the response to further LPS stimuli, we compared LPS-induced p38 MAPK phosphorylation in LPS-pretreated cells and untreated cells. With consideration for the temporal changes of p38 MAPK phosphorylation after LPS treatment in Fig. 4, LPS pretreatment was accomplished by being incubated with LPS for $2 \mathrm{~h}$ and washed with PBS. While LPS increased p38 MAPK phosphorylation at $15 \mathrm{~min}$ by 5 -fold over basal level in the cells that received no pretreatment, the stimulatory effect of LPS was markedly reduced in LPS-pretreated cells (Fig. 8A).

Next, we examined how LPS signaling is affected when ectodomain shedding of TLR4 is prohibited by depletion of ADAM17. We first compared the changes in p38 MAPK phosphorylation over time after LPS stimulation in the control cells and ADAM17depleted cells (Fig. 8B). HAECs were transfected with control-siRNA or ADAM17-siRNA, and then incubated with LPS for 15, 60 or 120 min. Western blot analysis revealed similar phosphorylation of p38 MAPK at 15 min after LPS treatment regardless of ADAM17 depletion. 
Fig. 8. LPS pretreatment attenuates the response to further LPS stimuli, while depletion of ADAM17 potentiates the cellular effects of LPS. (A) HAECs were pretreated with medium alone or LPS (100 ng/ml) for $2 \mathrm{~h}$, washed and then stimulated for $15 \mathrm{~min}$ with LPS $(100 \mathrm{ng} / \mathrm{ml})$. Whole cell lysates were immunoblotted with antibody to p-p38 MAPK or p38 MAPK. $\left(n=5,{ }^{*} p<0.05\right.$ compared with control, ${ }^{* *} \mathrm{p}<0.05$ as compared with LPS-stimulated cells that received no pretreatment) (B) HAECs were transfected with con-

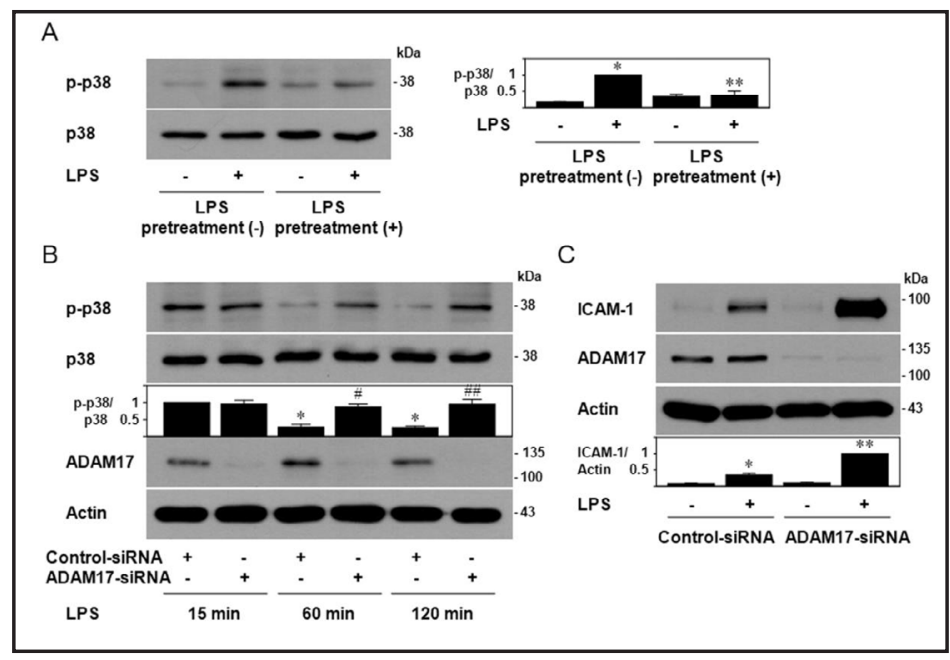
trol-siRNA or ADAM17-siRNA, and then incubated with LPS (100 ng/ml) for 15, 60 or $120 \mathrm{~min}$. Whole cell lysates were immunoblotted with antibody to p-p38 MAPK, p38 MAPK, ADAM17 or actin. (n=5, ${ }^{*} \mathrm{p}<0.05$ compared with control-siRNA at 15 min, ${ }^{\#} \mathrm{p}<0.05$ as compared with control-siRNA at $60 \mathrm{~min},{ }^{\# \#} \mathrm{p}<0.05$ as compared with control-siRNA at 120 min) (C) HAECs were transfected with control-siRNA or ADAM17-siRNA, and then incubated with or without LPS (100 ng/ml) for $24 \mathrm{~h}$. Whole cell lysates were immunoblotted with antibody to ICAM-1, ADAM17 or actin. ( $\mathrm{n}=3,{ }^{*} \mathrm{p}<0.05$ compared with control-siRNA only, ${ }^{* *} \mathrm{p}<0.05$ as compared with control-siRNA plus LPS).

In the control cells, there was a marked decline in phosphorylation of p38 MAPK over time. In the cells depleted of ADAM17, however, phosphorylation of p38 MAPK remained elevated at 60 and $120 \mathrm{~min}$.

We next compared LPS-induced ICAM-1 expression in the control cells and ADAM17depleted cells. In our previous study [16], LPS stimulated ICAM-1 expression, through TLR4-p38 MAPK axis, with a peak value at $8 \mathrm{~h}$ and then a significant decrease at $24 \mathrm{~h}$. HAECs were transfected with control-siRNA or ADAM17-siRNA, and then incubated with LPS for 24 $\mathrm{h}$ to determine the delayed effect of LPS. As shown in Fig. 8C, LPS-induced ICAM-1 expression was significantly elevated in the cells depleted of ADAM17 as compared with control cells.

\section{Discussion}

In the present study, we found that LPS rapidly induces ectodomain shedding of TLR4 in HAECs, which desensitizes the cells to LPS. ADAM17 was implicated in the ectodomain cleavage of TLR4.

A rapid loss of cell surface TLR4 after exposure to LPS was first reported in mouse peritoneal macrophages $[11,12]$. When the macrophages were stimulated with $100 \mathrm{ng} / \mathrm{ml}$ LPS, cell surface TLR4 expression began to decrease within $1 \mathrm{~h}$ and remained suppressed over $24 \mathrm{~h}$. In the subsequent other studies [10, 26], the loss of cell surface TLR4 after LPS stimulation in monocytes/macrophages was attributed to endocytosis of TLR4. Likewise, we also observed a rapid loss of cell surface TLR4 in HAECs after exposure to LPS, but the mechanism was different from that in monocytes/macrophages. TLR4 decreased rapidly in whole cell lysate upon exposure to LPS. The reduction in cellular TLR4 was accompanied by an increase in TLR4 immunoreactivity in the culture supernatant. The size of TLR4 in the culture supernatant detected by the monoclonal antibody recognizing the $\mathrm{N}$-terminus of TLR4 was $\sim 48 \mathrm{kDa}$. Considering that the size of the full-length TLR4 is $\sim 95 \mathrm{kDa}$, it indicates a fragment of TLR 4 containing $\mathrm{N}$-terminal portion produced by cleavage of the ectodomain region. The specificity of the TLR4 bands was validated by the finding that depletion of TLR4 by siRNA transfection resulted in a loss of both N-terminal fragment of TLR4 in the 


\section{Cellular Physiology Cell Physiol Biochem 2018;45:1851-1862 \\ \begin{tabular}{l|l} 
DOI: 10.1159/000487876 & and Biochemistry \\
Published online: March 05, 2018 & $\begin{array}{l}\text { O } 2018 \text { The Author(s). Published by S. Karger AG, Basel } \\
\text { www.karger.com/cpb }\end{array}$
\end{tabular} \\ Yang et al.: Ectodomain Shedding of TLR4 in Response to Lipopolysaccharide}

culture supernatant and TLR4 in whole cell lysates. Consistent with the Western blot data, immunofluorescent staining of TLR4 in non-permeabilized HAECs demonstrated a marked reduction of TLR4 at the cell surface after LPS treatment. The decrease in cellular TLR4 was maximal at $2 \mathrm{~h}$ and then began to return towards the basal level thereafter, which may be because the cleaved TLR4 was replenished later by newly synthesized TLR4.

Unlike in monocytes/macrophages, receptor endocytosis did not have the major role in the decrease of cell surface TLR4 following LPS stimulation in HAECs as the inhibition of endocytosis did not prevent it. Endothelial cells are different from monocytes/macrophages in the amount of CD14 expressed on the cell surface, which may make the difference. LPS-induced endocytosis of cell surface TLR4 is dependent on the presence of CD14 as TLR4 internalization is not observed in the cells deficient of CD14, but becomes evident after transfection of CD14 cDNA in CD14-deficient cells [26]. While CD14 is abundantly expressed on monocytes/macrophages (approximately 110, 000 molecules per monocyte/ macrophage), it is expressed at much lower level on endothelial cells $(2,000 \sim 2,500$ molecules per endothelial cell) [17]. Of the endothelial cells, HAECs were shown to express significantly lower amount of CD14 than microvascular endothelial cells [27].

Metalloproteases like ADAMs regulate the expression of receptors on the cell surface by enzymatic cleavage of the extracellular domains [4]. Diverse cell surface receptors such as TNF receptors and interleukin 6 receptor are substrates of ADAMs [28-31]. In the present study, LPS increased the activity of metalloprotease catalyzing the cleavage of ADAM17 substrate. Though the substrate can also be catalyzed by other MMPs, this increase in metalloprotease activity was completely prevented by siRNA depletion of ADAM17, indicating that ADAM17 accounted for the majority of LPS-induced metalloprotease activity. It is in agreement with the previous studies that demonstrated LPS rapidly increases ADAM17 activity [21, 32]. Ectodomain shedding of TLR4 following LPS stimuli was dependent on ADAM17 as it was completely prevented by specific depletion of ADAM17 by siRNA transfection as well as TAPI-2, a broad spectrum ADAM inhibitor. Recently, we reported that $1,25 \mathrm{D}_{3}$ induces ectodomain shedding of TLR4 in HAECs [16]. In this case, ADAM10, activated by extracellular $\mathrm{Ca}^{2+}$ influx, was implicated in ectodomain cleavage of TLR4. ADAM17 and ADAM10 are activated by different stimuli, but may catalyze the same substrate. For example, both phorbol 12-myristate 13-acetate and ionomycin cause ectodomain shedding of CD44, but it is mediated differently by ADAM17 and ADAM10, respectively [33]. Likewise, our data suggest that ADAM17 as well as ADAM10 are implicated in ectodomain shedding of TLR4 depending on the nature of stimuli to the cells.

On treatment of HAECs with LPS, p38 MAPK was markedly phosphorylated in 15 min and then the magnitude of this phosphorylation declined with time. The level of p38 MAPK phosphorylation at 15 min after LPS treatment was not affected by depletion of ADAM17, indicating p38 MAPK activation occurs independently of ADAM17. In contrast, the increase in ADAM17 activity by LPS was abolished by pretreatment with SB203580, a p38 MAPK inhibitor. The findings indicate that p38 MAPK phosphorylation preceeds ADAM17 activation. The mechanism of ADAM17 activation has not been fully understood, but p38 MAPK was shown to be related to activation of ADAM17 in the previous studies. In human monocytes [21], LPS up-regulated ADAM17 activity within 30 min without increasing cell surface ADAM17 expression, in which p38 MAPK activation was a prerequisite for the increase in ADAM17 activity. In C $\alpha$ cells [34], p38 MAPK activation caused an increase in mature ADAM17 on the cell surface. This study reported that p38 MAPK directly activates ADAM17 by phosphorylating $\mathrm{Thr}^{735}$ in the ADAM17 cytoplasmic domain, which suggests that other inflammatory stimuli activating p38 MAPK may also activate ADAM17. In support of it, TNF- $\alpha$ was shown to activate ADAM17 following activation of p38 MAPK in tubular epithelial cells [35]. In other studies [36, 37], however, the activation ADAM17 did not rely on its cytoplasmic domain or phosphorylation of $\mathrm{Thr}^{735}$. Thus, it remains to be investigated whether p38 MAPK directly participates in ADAM17 activation.

Depending on the site of cleavage, ectodomain shedding of a receptor results in inhibition or constitutive activation of the receptor. Loss of effective binding receptors causes decreased 


\section{Cellular Physiology Cell Physiol Biochem 2018;45:1851-1862 \begin{tabular}{l|l} 
and Biochemistry Published 10.1159/000487876 & $\begin{array}{l}\text { C) } 2018 \text { The Author(s). Published by S. Karger AG, Basel } \\
\text { www.karger.com/cpb }\end{array}$ \\
\hline
\end{tabular} \\ Yang et al.: Ectodomain Shedding of TLR4 in Response to Lipopolysaccharide}

response of the cells to the ligand [4]. In contrast, the removal of an inhibitory domain may cause constitutive activation of the receptor [38]. TLR4 consists of an extracellular domain, a transmembrane domain and a cytoplasmic domain [39]. The transmembrane and cytoplasmic domains of TLR4 were shown to have an intrinsic dimerization propensity leading to activation of the receptor, while the extracellular domain inhibited the spontaneous receptor dimerization [38]. The inhibitory part of the extracellular domain was about 20 amino acid residues near the transmembrane domain. In the present study, TLR4 ectodomain shedding after LPS treatment resulted in a blunted response of p38 MAPK phosphorylation to further LPS stimulation. Conversely, prevention of TLR4 ectodomain shedding by siRNA depletion of ADAM17 led to potentiation of LPS effects on p38 MAPK activation and ICAM-1 expression. The findings suggest that the cleavage of TLR4 desensitizes the cells to LPS by cutting the extracellular domain distal to the inhibition region of the receptor and thereby decreasing the number of effective receptors.

\section{Conclusion}

In summary, HAECs respond to LPS by rapid shedding of the ectodomain of TLR4 and thereby reduce the responsiveness to subsequent LPS exposure. ADAM17, activated following p38 MAPK, is implicated in the ectodomain cleavage of TLR4.

\section{Acknowledgements}

This study was supported by a grant (02-200) from the Asan Institute for Life Sciences (Seoul, Korea). The authors thank Moon Soo Young and Han Nam Jeong for excellent technical assistance.

\section{Disclosure Statement}

No conflict of interests exists.

\section{References}

1 Heine H, Rietschel ET, Ulmer AJ: The biology of endotoxin. Mol Biotechnol 2001;19:279-296.

-2 Chousterman BG, Swirski FK, Weber GF: Cytokine storm and sepsis disease pathogenesis. Semin Immunopathol 2017;39:517-528.

-3 Hare JF, Taylor K: Mechanisms of plasma membrane protein degradation: recycling proteins are degraded more rapidly than those confined to the cell surface. Proc Natl Acad Sci USA 1991;88:5902-5906.

4 Hayashida K, Bartlett AH, Chen Y, Park PW: Molecular and cellular mechanisms of ectodomain shedding. Anat Rec 2010;293:925-937.

-5 Choi H, Nguyen HN, Lamb FS: Inhibition of endocytosis exacerbates TNF- $\alpha$-induced endothelial dysfunction via enhanced JNK and p38 activation. Am J Physiol Heart Circ Physiol 2014;306:H1154-H1163.

6 Dri P, Gasparini C, Menegazzi R, Cramer R, Albéri L, Presani G, Garbisa S, Patriarca P: TNF-Induced shedding of TNF receptors in human polymorphonuclear leukocytes: role of the 55-kDa TNF receptor and involvement of a membrane-bound and non-matrix metalloproteinase. J Immunol 2000;165:2165-2172.

7 Płóciennikowska A, Hromada-Judycka A, Borzęcka K, Kwiatkowska K: Co-operation of TLR4 and raft proteins in LPS-induced pro-inflammatory signaling. Cell Mol Life Sci 2015;72:557-581.

8 Park BS, Lee JO: Recognition of lipopolysaccharide pattern by TLR4 complexes. Exp Mol Med 2013;45:e66.

-9 Park GS, Kim JH: LPS up-regulates ICAM-1 expression in breast cancer cells by stimulating a MyD88-BLT2ERK-linked cascade, which promotes adhesion to monocytes. Mol Cells 2015;38:821-828. 


\section{Cellular Physiology Cell Physiol Biochem 2018;45:1851-1862 \begin{tabular}{l|l} 
and Biochemistry Published online: March 05, 2018 & $\begin{array}{l}\text { (c) } 2018 \text { The Author(s). Published by S. Karger AG, Basel } \\
\text { www.karger.com/cpb }\end{array}$
\end{tabular} \\ Yang et al.: Ectodomain Shedding of TLR4 in Response to Lipopolysaccharide}

10 Husebye H, Halaas $\emptyset$, Stenmark H, Tunheim G, Sandanger $\emptyset$, Bogen B, Brech A, Latz E, Espevik T: Endocytic pathways regulate Toll-like receptor 4 signaling and link innate and adaptive immunity. EMBO J 2006;25:683-692.

11 Nomura F, Akashi S, Sakao Y, Sato S, Kawai T, Matsumoto M, Nakanishi K, Kimoto M, Miyake K, Takeda $\mathrm{K}$, Akira S: Cutting edge: endotoxin tolerance in mouse peritoneal macrophages correlates with downregulation of surface toll-like receptor 4 expression. J Immunol 2000;164:3476-3479.

12 Sato S, Nomura F, Kawai T, Takeuchi O, Mühlradt PF, Takeda K, Akira S: Synergy and cross-tolerance between toll-like receptor (TLR) 2- and TLR4-mediated signaling pathways. J Immunol 2000;165:70967101.

13 Rajaiah R, Perkins DJ, Ireland DD, Vogel SN: CD14 dependence of TLR4 endocytosis and TRIF signaling displays ligand specificity and is dissociable in endotoxin tolerance. Proc Natl Acad Sci USA 2015;112:83918396.

14 Lloyd-Jones KL, Kelly MM, Kubes P: Varying importance of soluble and membrane CD14 in endothelial detection of lipopolysaccharide. J Immunol 2008;181:1446-1453.

15 Zhao W, Ma G, Chen X: Lipopolysaccharide induced LOX-1 expression via TLR4/MyD88/ROS activated p38MAPK-NF- $\kappa B$ pathway. Vascul Pharmacol 2014;63:162-172.

16 Yang WS, Kim JJ, Han NJ, Lee EK, Park SK: 1,25-Dihydroxyvitamin D $_{3}$ attenuates the effects of lipopolysaccharide by causing ADAM10-dependent ectodomain shedding of toll-like receptor 4. Cell Physiol Biochem 2017;41:2104-2116.

17 Jersmann HP: Time to abandon dogma: CD14 is expressed by non-myeloid lineage cells. Immunol Cell Biol 2005;83:462-467.

18 Jersmann HP, Hii CS, Hodge GL, Ferrante A: Synthesis and surface expression of CD14 by human endothelial cells. Infect Immun 2001;69:479-485.

19 Lloyd KL, Kubes P: GPI-linked endothelial CD14 contributes to the detection of LPS. Am J Physiol Heart Circ Physiol 2006;291:H473-H481.

-20 Keck S, Müller I, Fejer G, Savic I, Tchaptchet S, Nielsen PJ, Galanos C, Huber M, Freudenberg MA: Absence of TRIF signaling in lipopolysaccharide-stimulated murine mast cells. J Immunol 2011;186:5478-5488.

21 Scott AJ, O’Dea KP, O’Callaghan D, Williams L, Dokpesi JO, Tatton L, Handy JM, Hogg PJ, Takata M: Reactive oxygen species and p38 mitogen-activated protein kinase mediate tumor necrosis factor $\alpha$-converting enzyme (TACE/ADAM-17) activation in primary human monocytes. J Biol Chem 2011;286:35466-35476.

22 Dreymueller D, Pruessmeyer J, Groth E, Ludwig A: The role of ADAM-mediated shedding in vascular biology. Eur J Cell Biol 2012;91:472-485.

23 Li D, Xiao Z, Wang G, Song X: Knockdown of ADAM10 inhibits migration and invasion of fibroblast-like synoviocytes in rheumatoid arthritis. Mol Med Rep 2015;12:5517-5523.

24 Yang WS, Han NJ, Kim JJ, Lee MJ, Park SK: TNF- $\alpha$ activates high-mobility group box 1 - toll-like receptor 4 signaling pathway in human aortic endothelial cells. Cell Physiol Biochem 2016;38:2139-2151.

-25 Kagan JC, Su T, Horng T, Chow A, Akira S, Medzhitov R: TRAM couples endocytosis of Toll-like receptor 4 to the induction of interferon- $\beta$. Nat Immunol 2008;9:361-368.

-26 Zanoni I, Ostuni R, Marek LR, Barresi S, Barbalat R, Barton GM, Granucci F, Kagan JC: CD14 controls the LPSinduced endocytosis of Toll-like receptor 4. Cell 2011;147:868-880.

-27 Lu Z, Li Y, Jin J, Zhang X, Lopes-Virella MF, Huang Y: Toll-like receptor 4 activation in microvascular endothelial cells triggers a robust inflammatory response and cross talk with mononuclear cells via interleukin-6. Arterioscler Thromb Vasc Biol 2012;32:1696-1706.

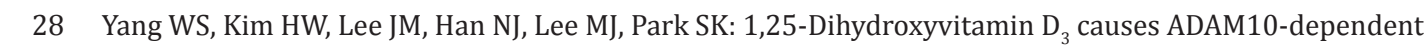
ectodomain shedding of tumor necrosis factor receptor 1 in vascular smooth muscle cells. Mol Pharmacol 2015;87:533-542.

-29 Yang WS, Moon SY, Lee MJ, Park SK: Epigallocatechin-3-gallate attenuates the effects of TNF- $\alpha$ in vascular endothelial cells by causing ectodomain shedding of TNF receptor 1. Cell Physiol Biochem 2016;38:19631974.

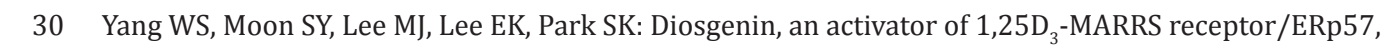
attenuates the effects of TNF- $\alpha$ by causing ADAM10-dependent ectodomain shedding of TNF receptor 1. Cell Physiol Biochem 2017;43:2434-2445. 


\section{Cellular Physiology Cell Physiol Biochem 2018;45:1851-1862 \begin{tabular}{l|l} 
DOI: 10.1159/000487876 & O 2018 The Author(s). Published by S. Karger AG, Basel \\
www.karger.com/cpb
\end{tabular} \\ Yang et al.: Ectodomain Shedding of TLR4 in Response to Lipopolysaccharide}

31 Matthews V, Schuster B, Schütze S, Bussmeyer I, Ludwig A, Hundhausen C, Sadowski T, Saftig P, Hartmann D, Kallen KJ, Rose-John S: Cellular cholesterol depletion triggers shedding of the human interleukin-6 receptor by ADAM10 and ADAM17 (TACE). J Biol Chem 2003;278:38829-38839.

-32 Robertshaw HJ, Brennan FM: Release of tumour necrosis factor $\alpha$ (TNF $\alpha$ ) by TNF $\alpha$ cleaving enzyme (TACE) in response to septic stimuli in vitro. Br J Anaesth 2005;94:222-228.

-33 Nagano O, Murakami D, Hartmann D, De Strooper B, Saftig P, Iwatsubo T, Nakajima M, Shinohara M, Saya H: Cell-matrix interaction via CD44 is independently regulated by different metalloproteinases activated in response to extracellular $\mathrm{Ca}^{2+}$ influx and PKC activation. J Cell Biol 2004;165:893-902.

-34 Xu P, Derynck R: Direct activation of TACE-mediated ectodomain shedding by p38 MAP kinase regulates EGF receptor-dependent cell proliferation. Mol Cell 2010;37:551-566.

35 Waheed F, Dan Q Amoozadeh Y, Zhang Y, Tanimura S, Speight P, Kapus A, Szászi K: Central role of the exchange factor GEF-H1 in TNF- $\alpha$-induced sequential activation of Rac, ADAM17/TACE, and RhoA in tubular epithelial cells. Mol Biol Cell 2013;24:1068-1082.

-36 Hall KC, Blobel CP: Interleukin-1 stimulates ADAM17 through a mechanism independent of its cytoplasmic domain or phosphorylation at threonine 735. PLoS One 2012;7:e31600.

-37 Schwarz J, Broder C, Helmstetter A, Schmidt S, Yan I, Müller M, Schmidt-Arras D, Becker-Pauly C, Koch-Nolte F, Mittrücker HW, Rabe B, Rose-John S, Chalaris A: Short-term TNF $\alpha$ shedding is independent of cytoplasmic phosphorylation or furin cleavage of ADAM17. Biochim Biophys Acta 2013;1833:3355-3367.

-38 Panter G, Jerala R: The ectodomain of the toll-like receptor 4 prevents constitutive receptor activation. J Biol Chem 2011;286:23334-23344.

-39 Vaure C, Liu Y: A comparative review of toll-like receptor 4 expression and functionality in different animal species. Front Immunol 2014;5:316. 